\title{
CONTEXTUALIZAÇÃO E AVANÇOS NO TRATAMENTO DA HEPATITE C: UMA REVISÃO DA LITERATURA
}

\section{BACKGROUND AND ADVANCES IN HEPATITIS C TREATMENT: A LITERATURE REVIEW}

\author{
Vinicius Lins FERREIRA ${ }^{{ }^{*}}$; Roberto PONTAROLO ${ }^{1}$
}

1 - Programa de Pós-Graduação em Ciências Farmacêuticas - Universidade Federal do Paraná

Autor para correspondência: vinicius_lins1991@hotmail.com

\section{RESUMO:}

O objetivo deste trabalho foi realizar uma revisão da literatura sobre hepatite $\mathrm{C}$ e buscar evidências sobre diferenças de desempenho entre as terapias baseadas no uso de interferon e terapias livres de interferon. Para alcance desse objetivo foi feito uma busca nas bases Medline, Scopus, Web of Science e Scielo utilizando os termos "hepatitis C", "treatment", "interferon-free", "review" e "clinical trial". A primeira parte deste trabalho apresenta uma revisão das características, epidemiologia e diagnóstico da hepatite C. A segunda parte deste trabalho teve como foco a evolução do tratamento para hepatite C. Por muitos anos, o tratamento farmacológico utilizado teve como base o uso de interferon, que é bem conhecido por causar eventos adversos com frequência, por contraindicações e casos de índices não satisfatórios de eficácia. Como principal desfecho, as taxas de resposta virológica sustentada foram consideradas satisfatórias nos pacientes tratados com terapias livres de interferon. Essas novas opções terapêuticas foram introduzidas recentemente e demonstraram melhores resultados, perfil de segurança e eficácia, e podem ser uma boa opção de tratamento.

Palavras-chave: hepatite $\mathrm{C}$, revisão, tratamento, livre de interferon

\section{ABSTRACT:}

The aim of this study was to conduct a literature review about hepatitis $C$ and find evidences of differences in performance of interferon based therapies and interferon-free therapies. Search was performed in Medline, Scopus, Web of Science and Scielo electronic databases using as terms "hepatitis C", "treatment", "interferon-free", "review" and "clinical trial". The first part of this study presented a review of the characteristics, evolution, epidemiology and diagnosis of hepatitis $\mathrm{C}$. The second part of this study focused on evolution on hepatitis $\mathrm{C}$ treatment. For many years, treatment was based on the use of interferon, which is wellknown due to it many side effects, contraindications and not satisfactory efficacy profile. As main outcome, sustained virologic rates were considerate satisfactory in patients that received interferon-free therapies. In the last years, the introduction of interferon-free treatment presented better results and profile of safety and efficacy, and can be a good treatment option.

Keywords: hepatitis C, review, treatment, interferon-free 


\section{INTRODUÇÃO}

Hepatites virais são um grave problema de saúde pública que atinge milhões de pessoas em todo o mundo. São um conjunto de doenças causadas por diferentes agentes etiológicos que possuem semelhanças por atingirem o tecido hepático, porém apresentam características epidemiológicas, clínicas e laboratoriais muito distintas (BRASIL, 2005).

Mais especificamente, a hepatite $\mathrm{C}$ atinge cerca de $3 \%$ da população mundial, caracterizando-se como um relevante problema de saúde. Cabe destacar também que ao longo dos anos, o tratamento dos pacientes infectados com o vírus da hepatite $\mathrm{C}$ (VHC) avançou consideravelmente (EASL, 2011).

O tratamento farmacológico mais utilizado para a hepatite $C$, por muitos anos, foi baseado na combinação de interferon (IFN) e ribavirina (RBV) (OLIVEIRA et al., 2015). O regime de tratamento à base de IFN pode ser problemático para os pacientes com cirrose hepática devido a maior frequência de efeitos adversos, contraindicações e da inconveniência de injeções semanais (SULKOWSKI et al., 2011).

Além do problema de perfil de segurança das terapias que tem como base o uso IFN, a efetividade pode ser limitada já que em muitos casos esses medicamentos não são suficientes para o controle do vírus, principalmente em pacientes cujo estado clínico é mais grave. Como resultado, muitos infectados são incapazes de receber esses medicamentos ou não alcançam resultados terapêuticos satisfatórios (WHO, 2014).

Recentemente, o surgimento de novos fármacos como sofosbuvir (SOF) e daclatasvir (DAC) associados a um regime medicamentoso livre de interferon podem representar uma solução para essa problemática. A introdução de novas terapias livres de IFN tem crescido consideravelmente no tratamento da hepatite C. Esses medicamentos podem ser combinados, com ou sem o uso de RBV, e demonstram resultados positivos (ZEUZEM et al., 2015).

Nesse contexto, a literatura científica ainda carece de informações concisas e relevantes sobre essas terapias, que sejam capazes de embasar apropriadamente tomadas de decisão em saúde. Esse trabalho teve como objetivos: produzir um artigo de revisão da literatura sobre hepatite $\mathrm{C}$ e buscar evidências sobre diferenças de desempenho entre as terapias com base no uso de interferon e livres de interferon.

\section{METODOLOGIA}

Trata-se de um estudo bibliográfico narrativo e exploratório. A revisão bibliográfica 
foi realizada nas bases de dados Medline, Scopus, Web of Science e Scielo, utilizando os seguintes termos: hepatitis $C$, treatment, interferon-free, systematic review e clinical trial. Foram considerados estudos originais e de revisões, publicados com data anterior a junho de 2016. Os critérios de inclusão compreenderam a disponibilidade eletrônica e abordagem direta do tema. Foram excluídos estudos que não estavam relacionados com o tema.

\section{REVISÃO DA LITERATURA}

\subsection{Hepatite C}

\subsubsection{O vírus da hepatite C, epidemiologia e vias de transmissão}

$\mathrm{O}$ vírus da hepatite $\mathrm{C}$ pertence à família Flaviviridae, e foi primeiramente isolado a partir do soro de um portador de hepatite não A e não B. O VHC é um vírus composto de RNA e envelope de aproximadamente 9,6 kilobase (kb) (CHOO et al., 1989). Este envelope é formado por duas glicoproteínas, E1 e E2, as quais são unidas na forma de heterodímeros e estabilizadas por pontes de dissulfeto. Essas proteínas, em conjunto com lipídeos e receptores na membrana do hospedeiro, são responsáveis pela entrada do vírus nas células em um processo mediado por quinases. A forma ativa do vírus aproveita-se de partículas lipídicas do organismo hospedeiro para se direcionar as células alvo, que são as células hepáticas (hepatócitos) (FELMLEE et al., 2013; LINDENBACH; RICE, 2013).

A replicação do vírus da hepatite $C$ apenas é possível no interior de células hepáticas. Apesar disso, o VHC pode estar presente em outras células e tecidos, os quais atuam como reservatório natural para permanência do vírus no organismo hospedeiro e possível transmissão para os hepatócitos (BLAISING; PÉCHEUR, 2013).

O RNA viral é responsável pela tradução de algumas proteínas importantes para o funcionamento do vírus, sendo três proteínas estruturais e sete proteínas não estruturais. As estruturais compõem o envelope viral (E1 e E2) e capsídeo (core). As proteínas não estruturais são importantes para o ciclo viral (replicação viral) e incluem: p7 (canal iônico), NS2 (proteína transmembrana com atividade de auto-protease), NS3 (possui atividade protease e helicase a qual é complexada a proteína NS4A), NS4A (cofator de NS3), NS4B (proteína de membrana), NS5A (fosfoproteína moduladora) e NS5B (RNA polimerase que catalisa amplificação do genoma do vírus) (BARTENSCHLAGER; COSSET; LOHMANN, 2010; BUHLER; BARTENSCHLAGER, 2012). 
Assim, motivados pela complexidade da organização estrutural do VHC, foram desenvolvidos fármacos que são utilizados no combate a esse vírus que possui diversos alvos, sendo os principais as proteínas envolvidas na replicação viral NS3, NS4A, NS5A e NS5B (LANGE et al., 2014).

O VHC é classificado em seis genótipos principais e vários subtipos, sendo os genótipos 1, 3 e 4 com maior distribuição mundial (SMITH et al., 2014). É estimado que aproximadamente 185 milhões de pessoas em todo o mundo estejam cronicamente infectados com o VHC e que cerca de 350 mil morrem a cada ano. As regiões de maior prevalência são a Ásia, norte da África e Oriente Médio. A Ásia é o continente que possui maior número de infectados no mundo, mas isso também está ligado ao tamanho populacional (WHO, 2014).

No Brasil, a predominância também é do genótipo do tipo 1, principalmente subtipos 1a e 1b (FOCACCIA et al., 2004; CAMPIOTTO et al., 2005). O Sistema de Informação de Agravos de Notificação (SINAN) informou mais de 80 mil casos confirmados de hepatite $C$ no Brasil entre os anos de 1999 e 2011, sendo grande parte localizados nas regiões sudeste $(67,3 \%)$ e sul (22,3\%). Nesse período, houve maior incidência em homens (aproximadamente 60\%), comparado aos casos em mulheres (aproximadamente $40 \%$ ). Isso representa uma queda desta razão, já que no final da década de 90 , a razão era de 2 homens infectados para cada mulher infectada. A incidência do VHC também é maior em pessoas acima dos 40 anos e está mais presente em brancos. O maior número de notificações é na forma clínica crônica, sendo baixo o número de casos agudos ou fulminantes (menor que 3\%). Foram também relatados 30.931 óbitos por hepatite $C$ no período mencionado, principalmente nas regiões sul e sudeste (BRASIL, 2012).

As principais formas de infecção pelo VHC são através do uso de drogas injetáveis e inalatórias, transmissão vertical da mãe para o feto, contato sexual e prática de procedimentos realizados sem a devida segurança como cirurgias, hemodiálise, transfusão sanguínea, acupuntura, tatuagens e piercings (MENDES-CORRÊA; BARONE, 2005). É comum a co-infecção do VHC com outros vírus, como o da hepatite B, Síndrome da Imunodeficiência Adquirida (AIDS) e tuberculose. Isso acontece principalmente pela semelhança nas rotas de transmissão (WHO, 2014). Além disso, deve-se ter atenção especial em alguns casos em que a vulnerabilidade ao vírus é maior, como no caso de moradores de ruas e pessoas privadas de liberdade. Estudos apontam prevalência do vírus nesses grupos populacionais, pois muitas dessas pessoas possuem histórico de compartilhamento de injetáveis e uso de drogas (CARDOSO, 2005). Ainda não existe 
vacina disponível para hepatite C. Assim, a principal forma de prevenção é através da diminuição do risco de exposição ao vírus, a qual se torna difícil pela existência de inúmeras rotas de transmissão (WHO, 2014).

\subsubsection{Diagnóstico da hepatite C}

O diagnóstico laboratorial da infecção pelo VHC é feito por testes sorológicos para detecção de anticorpos específicos (anti-VHC) ou do RNA do VHC, como por exemplo por meio do Teste de Ácido Nucleico (NAT) (THOMSON et al., 2011). Alguns outros testes auxiliam o diagnóstico. Os níveis séricos de algumas aminotransferases como ALT (alanina aminotransferase) podem estar elevados e alterações nos níveis de bilirrubina, proteínas séricas, fosfatase alcalina e hemograma complementam o diagnóstico (BRASIL, 2011).

A presença de anti-VHC não necessariamente significa uma infecção ativa. Assim, pode ser interpretada como um contato prévio com o vírus e, para confirmação da infecção, deve-se utilizar testes moleculares que possam detectar ácidos nucleicos do vírus. O NAT também deve ser aplicado em pacientes imunodeprimidos, já que esses podem apresentar diminuição ou ausência de anticorpos (BRASIL, 2012).

\subsubsection{Hepatite C aguda e crônica}

A hepatite $C$ aguda é caracterizada pela presença do vírus por até seis meses após o contato, podendo ser assintomática e atingir a cura espontânea. Porém, existem casos não tratados em que o VHC persiste no infectado por toda vida e esses são considerados crônicos (GERLACH et al., 2003). O quadro clínico da hepatite C aguda se assemelha a de outras infecções hepáticas virais o que torna difícil o diagnóstico. Os principais sintomas são: icterícia, astenia, anorexia, prurido, artralgia, acolia, colúria e dor abdominal. A hepatite C aguda pode causar danos graves, mas a falência hepática fulminante dificilmente acontece (BRASIL, 2011).

A presença do vírus, muitas vezes, não é percebida pelos pacientes, que permanecem infectados durante muitos anos. A cura espontânea ocorre em 15-45\% no período de seis meses. Em outros casos em que não acontece a cura e não se tem o tratamento adequado, o VHC persiste por toda vida ou podem alcançar a forma crônica (WHO, 2014).

Os principais agravantes da hepatite C crônica são a possibilidade de desenvolvimento 
de cirrose, falência hepática fulminante e hepatocarcinoma (ALAZAWI et al., 2010). O aparecimento desses sinais está relacionado com certas características e comportamento dos infectados, tais como uso em excesso de bebida alcoólica, co-infecção com vírus da hepatite $B$ ou vírus da imunodeficiência humana e imunossupressão (FREEMAN et al., 2003). Ainda é possível o aparecimento de sinais e sintomas extra-hepáticos, sendo os mais comuns crioglobulinemia, síndrome de Sjögren, reação autoimune, artralgia e púrpura (BRASIL, 2009).

Algumas escalas são utilizadas para avaliar a severidade da doença hepática. Há portanto a necessidade de se identificar pacientes cirróticos antes da escolha da terapia, pois a resposta do paciente a determinada medicação pode variar de acordo com o grau de fibrose das células hepáticas. Uma ferramenta bastante conhecida e utilizada para medir a progressão da fibrose é a escala METAVIR, classificada em quatro estágios: F0 (sem fibrose), F1 (fibrose portal sem septos), F2 (fibrose portal com raro septos), F3 (numerosos septos sem cirrose) e F4 (cirrose) (EASL, 2011).

Para a cura e/ou controle da doença faz-se necessário o uso de medicamentos. Por muitos anos a terapia foi baseada no uso de IFN e RBV. Novas drogas foram desenvolvidas e inseridas no regime de tratamento como sofosbuvir e daclatasvir. Esses medicamentos demonstraram maior perfil de segurança e eficácia (FELD et al., 2014).

\subsubsection{Desfechos de eficácia e segurança}

Para um melhor entendimento dos desfechos clínicos é necessário o conhecimento de alguns termos utilizados nos ensaios clínicos para hepatite C. Alguns dos principais desfechos de eficácia e segurança empregados nesses tipos de estudos são: RVS (resposta virológica sustentada - sustained viral response), RVR (resposta virológica rápida - rapid viral response) e falha virológica durante ou após o termino do tratamento (viral breakthrough ou viral relapse) (WHO, 2014).

O principal objetivo da terapia para hepatite $C$ é atingir a chamada resposta virológica sustentada que pode ser entendida como a não detecção do RNA viral do VHC após o fim do tratamento (RVS4, RVS12 e RVS24 são respectivamente a não detecção do RNA viral após 4, 12 e 24 semanas após termino do tratamento) (EASL, 2011).

RVR é a não detecção do RNA viral do VHC na quarta semana de tratamento. RVS ao final do tratamento é denominada como término do tratamento (end of treatment). Nem sempre a terapia é eficaz e em alguns casos ocorre a chamada falha virológica, que é 
definida como o aparecimento do RNA viral após esse ter sido indetectável, seja durante ou após o termino da terapia (respectivamente viral breakthrough ou viral relapse). Essas respostas são consideradas importantes no monitoramento da terapia e constituem um resultado indireto do sucesso terapêutico (EASL, 2011).

\subsection{Tratamento da hepatite C}

\subsubsection{Tratamento para hepatite $\mathbf{C}$ aguda}

O tratamento na fase aguda tem como objetivo reduzir o risco de progressão para forma crônica. Quando detectado precocemente, as chances de controle são maiores e estão associadas a uma maior RVS. Para pacientes sintomáticos é indicado o início do tratamento após 12 semanas do início dos sintomas. Para pacientes assintomáticos é recomendado o início imediato após o diagnóstico.

De forma geral, o tratamento nessa fase consiste da associação de peginterferon (PEG-IFN) com RBV por 24 semanas (BRASIL, 2015).

\subsubsection{Tratamento da hepatite $\mathbf{C}$ crônica com terapias baseadas no uso de interferon}

No início da década de 90, foi aprovado o primeiro fármaco para o tratamento da hepatite C: interferon. O uso de IFN significou um grande avanço, já que não existia nenhum tratamento disponível na época. Apesar disso, o uso de IFN, uma citocina com ampla e inespecífica ação antiviral, foi relacionado a um baixo sucesso terapêutico, reduzido perfil de tolerabilidade e segurança (POORDAD; DIETERICH, 2012).

De 2001 a 2011, utilizou-se associação entre PEG-IFN e RBV para tratamento da hepatite $\mathrm{C}$. Alguns estudos apontam que essa combinação apresentava resposta virológica sustentada média entre $40 \%$ a $50 \%$ para infectados pelo genótipo 1 do vírus e de $70 \%$ a 80\% para genótipo do tipo 2 e 3 (MANNS et al., 2001; FRIED et al., 2002).

O IFN está relacionado a muitos efeitos adversos como depressão, resposta autoimune, sintomas semelhantes à gripe e desordens hematológicas, além de possuir diversas contra-indicações. Da mesma forma, a RBV está associada a eventos não desejados como rash, hemólise, teratogênese, anemia. Dessa maneira, muitos infectados são intolerantes ou não podem fazer uso dessa associação (WARD; KUGELMAS, 2005). 
A limitação desses medicamentos tanto em relação à eficácia quanto a segurança estimulou a busca por novos fármacos. Assim, em 2011, foram aprovados dois novos medicamentos antivirais de ação direta de primeira geração (DAA - Direct Acting Antivirals): boceprevir (BOC) e telaprevir (TVR). O alvo desses novos agentes são proteínas envolvidas na replicação viral (NS3/4A) (KWO et al., 2010).

Porém, as monoterapias de BOC e TVR não são suficientes para garantir uma RVS satisfatória e podem estar associadas a resistência viral (AGHEMO; COLOMBO, 2011). Assim, esses medicamentos necessitam ser combinados em terapias duplas ou triplas com PEG-IFN e RBV para garantir aumento da RVS. No entanto, isso pode acarretar o aparecimento de eventos indesejáveis como anemia, rash e disgeusia. Para dificultar ainda mais a adesão ao tratamento, essas combinações duplas e triplas requerem injeções semanais de IFN por 24 a 48 semanas, além de três comprimidos por dia de RBV e até quatro de BOC ou TVR (KWO et al., 2010; JACOBSON et al., 2011).

No Brasil, a inclusão dos DAA de primeira geração BOC e TVR, ocorreu através da Portaria $\mathrm{n}^{\circ}$ 20, de 25 de julho de 2012 da Secretaria de Ciência, Tecnologia e Insumos Estratégicos (SCTIE/MS). Em casos mais graves, como em monoinfectados pelo genótipo 1, de fibrose avançada (Metavir F3 e F4) e cirrose hepática compensada, utiliza-se um desses DAA em associação com peginterferon + ribavirina (PR), formando assim uma terapia tripla (BRASIL, 2013).

Em 2013, o fármaco simeprevir (SMV), um DAA de segunda geração foi aprovado em combinação com PR. Apesar de demonstrar uma boa RVS para infectados com o genótipo 1b (>80\%), infectados pelo genótipo 1a apresentavam uma diminuição da RVS devido a um polimorfismo, que quando presente diminui a RVS para 58\% (BAE et al., 2010; FRIED et al., 2013). Motivados por isso, outros DAA foram desenvolvidos (segunda geração), como sofosbuvir (SOF), um inibidor de polimerase NS5B (LAWITZ; LALEZARI; et al., 2013).

A combinação de SOF ou SMV com PEG-IFN + RBV oferecia aos pacientes um tratamento mais curto, eficaz e seguro do que associações anteriores. Mesmo assim, ainda permaneciam alguns eventos adversos (EA) e intolerância por alguns pacientes causados pelo uso de IFN (YAU; YOSHIDA, 2014).

Alguns estudos clínicos têm demonstrado as taxas de eficácia e segurança dessas terapias baseadas no uso de IFN:

- A comparação da eficácia e segurança de PEG-IFN alfa-2b com ou sem RBV por 24 ou 48 semanas foi realizada por Poynard e colaboradores (1998) em 
mais de 800 pacientes. Apesar de que a combinação dos medicamentos terem apresentado melhor resposta comparada ao grupo que utilizava apenas PEGIFN, os índices de RVS foram inferiores a $50 \%$. Diversos eventos colaterais foram relatados, como por exemplo: dispneia, faringite, prurido, erupção cutânea, náuseas, insônia e anorexia. A descontinuação por efeitos colaterais teve maior frequência na combinação das drogas (19\%) e monoterapia (13\%) cujo tempo de tratamento foi de 48 semanas (POYNARD et al., 1998).

- Witthoft e colaboradores (2007) estudaram a eficácia e segurança de PEG-IFN alfa-2a e RBV em portadores crônicos de hepatite $C$ por 24 ou 48 semanas. A RVS foi alcançada em menos da metade dos pacientes (48\%), confirmando um risco benefício já conhecido. Os resultados demonstram uma alta incidência de efeitos colaterais, principalmente nas 12 primeiras semanas de tratamento. Os eventos adversos relatados em pelo menos $15 \%$ dos pacientes foram dores de cabeça, sintomas semelhantes à gripe, leucopenia, alopecia, depressão, náusea, anemia, fadiga, pirexia, diarréia, trombocitopenia, entre outros.

- Em 2010, Kwo e colaboradores analisaram a eficácia e segurança da terapia tripla PR + BOC. Os resultados apontaram que a inclusão de BOC ao tratamento padrão (PEG-IFN+RBV) dobraram a RVS (que variou de $40-80 \%$ a depender da dose e tempo de tratamento - até 48 semanas) quando comparada ao regime sem BOC (inferior a 50\%). Apesar disso, ainda são relatados diversos eventos adversos em grande proporção como anemia, disgeusia, fadiga, dor de cabeça, diarreia, pirexia, alopecia, insônia e resfriado. A descontinuação do tratamento ocorreu em aproximadamente $15 \%$ dos pacientes que faziam parte do grupo receberam BOC.

- O ensaio clínico RESPOND-2 realizado por Bacon e colaboradores em 2011, também mostrou que a adição de BOC ao tratamento padrão (PEG-IFN+RBV) aumentou a RVS (aproximadamente 60\%), comparada com o grupo sem o BOC (menor do que 25\%). Ainda assim, persistiram eventos adversos em parte dos pacientes como anemia, sintomas semelhantes à gripe, rash, disgeusia e pele seca. Isto levou a descontinuação do tratamento em parte dos participantes que utilizaram BOC (10-12\%).

- Os resultados de Kumada e colaboradores (2012) demonstram uma superioridade da RVS da terapia tripla de TVR + PR (73\%) comparado ao grupo que não recebeu esse inibidor de protease (49\%). Apesar disso, os pacientes 
necessitaram de um acompanhamento cuidadoso devido a presença de eventos adversos como desordens na pele, anemia e outros problemas hematológicos (44). Em 2012, um ensaio clínico trouxe resultados semelhantes, sendo anemia a principal causa de descontinuação do tratamento.

\subsubsection{Tratamento da hepatite C crônica com terapias livres de interferon}

Terapias para hepatite $C$ baseadas no uso de interferon possuem limitação quanto a segurança, eficácia e tolerabilidade, e isto conduziu ao desenvolvimento de novos medicamentos (POORDAD; DIETERICH, 2012).

Terapias livres de IFN, e em algumas situações sem RBV, favorecem a adesão ao tratamento por proporcionarem maior tolerância e por apresentarem menor frequência de administração de comprimidos. Associados a isso, está a possiblidade de alcance de maiores índices de RVS (EVERSON et al., 2014).

No Brasil, até junho de 2016 estão disponíveis os seguintes DAA de segunda geração: sofosbuvir, daclatasvir e simeprevir (BRASIL, 2015).

- Pearlman e colaboradores (2015) compararam a segurança e eficácia entre um grupo de pacientes que receberam SOF + SMV (grupo 1) e outro que recebeu PR + SOF (grupo 2). O primeiro grupo apresentou maior RVS (93\%) em comparação com o grupo 2 (75\%). O segundo grupo apresentou maior quantidade de falha virológica, descontinuação e eventos adversos. Alguns desses efeitos colaterais, como anemia, insônia, náusea, fadiga, astenia, febre, sintomas semelhantes à gripe e mialgia, estiveram presente em proporção significativa no segundo grupo. Não houve descontinuação por eventos colaterais no primeiro grupo.

- O estudo VALENCE (2014) com participação de mais de 400 pacientes avaliou o uso de SOF com ou sem RBV em portadores crônicos de hepatite C. A RVS encontrada foi de $93 \%$ no grupo dos portadores do genótipo 2 do VHC e $85 \%$ do genótipo 3. Os eventos adversos mais comuns foram dor de cabeça, astenia, náusea, fadiga e prurido. A combinação teve boa aceitação e apenas $1 \%$ dos pacientes deixaram o tratamento por eventos adversos (YOUNOSSI et al., 2014). 
- Jacobson e colaboradores (2013) demonstraram a eficácia e segurança do SOF em quase 300 portadores dos genótipos 2 e 3 do VHC. O grupo de pacientes que não tinham opção de uso de PEG-IFN apresentaram RVS de quase $80 \%$. Outros pacientes anteriormente medicados com PR foram divididos em mais dois grupos: 12 semanas (RVS de 50\%) e 16 semanas de tratamento (RVS de $73 \%$ ). O nível de descontinuação foi menor que $2 \%$ e as principais reações adversas notificadas foram dor de cabeça, insônia, fadiga, náusea e insônia.

- O ensaio clinico SAPPHIRE-I (2014) investigou o perfil da combinação paritaprevir + ritonavir + ombitasvir + dasavuvir (PrOD) com ribavirina em portadores do genótipo 1 do VHC previamente não tratados. Nesse grupo, a RVS12 foi de $96,2 \%$. Os efeitos colaterais com frequência significativa em comparação com o grupo placebo foram: náusea, prurido, insônia, diarreia e astenia. $O$ índice de descontinuação foi menor que 1\% nos grupos (FELD et al., 2014).

- Manns e coloboradores (2014) demonstraram que o regime DAC + asunaprevir (ASU) conduzem a altos índices de RVS12 (82-90\%) e foram bem tolerados pelos mais de 700 participantes. A descontinuação por eventos adversos ocorreu em menos de $3 \%$.

- O ensaio FISSION (2013) estudou pacientes portadores dos genótipos 2 e 3 do VHC. Os participantes foram divididos em dois grupos: 1) SOF + RBV por 12 semanas e 2) PEG-IFN alfa-2a + RBV por 24 semanas. Após doze semanas os grupos alcançaram respostas semelhantes (67\%). Porém, o primeiro grupo apresentou melhor perfil de segurança devido à menor taxa de reações adversas e de descontinuação ao tratamento (1\% para o grupo 1 e $11 \%$ para o grupo 2) (LAWITZ et al., 2014).

- O estudo randomizado COSMOS (2014) avaliou a eficácia da combinação SOF + SMV em mais de 300 pacientes. A RVS12 foi alcançada em 92\% dos participantes. Os eventos adversos mais comuns foram fadiga, dor de cabeça e náusea. A média de descontinuação nos grupos foi de $2 \%$ (LAWITZ et al., 2014).

- Um ensaio clínico randomizado realizado no Japão avaliou a eficácia e segurança da terapia DAC + ASU em 119 pacientes. Aproximadamente 90\% dos pacientes alcançaram a RVS12 e apenas 5\% descontinuaram por EA. (Kumada et al., 2016) 
- Um estudo multicêntrico conduzido na Europa e Oceania avaliou eficácia e segurança da combinação LED + SOF em 333 pacientes. Desse total, 92\% dos pacientes obtiveram cura da doença, sendo que apenas $2 \%$ descontinuaram por EA(MANNS et al., 2016) .

- O estudo ALLY-3+ realizado na Australia e França avaliou a terapia DAC + SOF + RBV por 12 ou 16 semanas. As taxas de RVS12 foram respectivamente de $87 \%$ e $92 \%$ para os pacientes tratados por 12 ou 16 semanas. EA foram relatados em $90 \%$ da população avaliada, porém não houveram descontinuações por motivos de segurança (LEROY et al., 2016) .

\section{CONSIDERAÇÕES FINAIS}

Como desfecho principal da hepatite C, as taxas de RVS12 foram consideradas satisfatórias (superiores a 70\%) nos pacientes tratados com terapias livres de interferon. Além disso, os índices encontrados foram superiores à média de RVS (40-60\% para o genótipo 1) alcançado por terapias antigas, como telaprevir e boceprevir, que tinham como base a associação com IFN e ribavirina (CAMMA et al., 2012; SHAHID et al., 2016).

$A$ hepatite $C$ crônica é uma doença que quando não tratada pode agravar-se e levar a diversas situações sérias, inclusive a morte do paciente. Assim, o tratamento deve ser iniciado o quanto antes a fim de evitar a progressão da doença.

Os ensaios clínicos randomizados que abordaram tratamentos para hepatites $\mathrm{C}$ livres de interferon mostraram eficácia e segurança superiores comparados com aqueles que utilizavam IFN e uma menor duração de tratamento e podem ser uma ótima opção para cura da hepatite $\mathrm{C}$.

\section{REFERÊNCIAS}

AGHEMO A., COLOMBO M. A 13-day, interferon-free regimen for chronic hepatitis C genotype 1 patients: Between fear and hope. Gastroenterology. 2011; 141(1):396-399. DOI: 10.1053/j.gastro.2011.05.013.

ALAZAWI W., CUNNINGHAM M., DEARDEN J., FOSTER G. R. Systematic review: outcome of compensated cirrhosis due to chronic hepatitis $\mathrm{C}$ infection. Aliment Pharmacol Ther. 2010; 32(3):344-355. DOI: 10.1111/j.1365-2036.2010.04370.x 
BACON B. R., et al. Boceprevir for previously treated chronic HCV genotype 1 infection. $\mathrm{N}$ Engl J Med. 2011; 364(13):1207-1217. DOI: 10.1056/NEJMoa1009482

BAE A., et al. Susceptibility of treatment-naive hepatitis $\mathrm{C}$ virus (HCV) clinical isolates to HCV protease inhibitors. Antimicrob Agents Chemother. 2010;54(12):5288-5297. DOI: 10.1128/AAC.00777-10.

BARTENSCHLAGER R., COSSET F. L., LOHMANN V. Hepatitis C virus replication cycle. J Hepatol. 2010; 53(3):583-585. DOI: 10.1016/j.jhep.2010.04.015

BLAISING J, PÉCHEUR E-I. Lipids - A key for hepatitis $C$ virus entry and a potential target for antiviral strategies. Biochimie. 2013;95(1):96-102. DOI: 10.1016/j.biochi.2012.07.016

BRASIL. Ministério da Saúde. Secretaria de Vigilância em Saúde. Departameto de DST, AIDS e Hepatites Virais. Protocolo clínico e diretrizes terapêuticas para hepatite viral c e coinfecções. Ministério da Saúde. Brasília - DF. 2011.

BRASIL. Ministério da Saúde. Secretaria de Vigilância em Saúde. Boletim Epidemiológico - Hepatites Virais. Brasília: Ministério da Saúde. 2012.

BRASIL. Ministério da Saúde. Secretaria de Vigilância em Saúde. Departamento de Vigilância Epidemiológica.Hepatites virais : o Brasil está atento / Ministério da Saúde, Secretaria de Vigilância em Saúde, Departamento de Vigilância Epidemiológica. - Brasília: Ministério da Saúde. 2005.

BRASIL. Ministério da Saúde. Secretaria de Vigilância em Saúde. Departamento de Vigilância Epidemiológica. Guia de vigilância epidemiológica. 7. ed. Brasília: Ministério da Saúde. 2009.

BRASIL. Ministério da Saúde. Secretaria de Vigilância em Saúde. Departamento de DST, Aids e Hepatites Virais. Protocolo Clínico e Diretrizes Terapêuticas para Hepatite C e Coinfecções/ Ministério da Saúde, Secretaria de Vigilância em Saúde, Departamento de DST, Aids e Hepatites Virais. - Brasília: Ministério da Saúde. 2015:101p. 
BRASIL. MINISTÉRIO DA SAÚDE. Secretaria de Vigilância em Saúde. Suplemento 1 do Protocolo clínico e diretrizes terapêuticas para hepatite viral C e coinfecções : manejo do paciente infectado cronicamente pelo genótipo 1 de HCV e fibrose avançada. Brasília: Ministério da Saúde, 2013.

BUHLER S., BARTENSCHLAGER R. New targets for antiviral therapy of chronic hepatitis C. Liver Int. 2012;32 Suppl 1:9-16. DOI: 10.1111/j.1478-3231.2011.02701.x.

CAMMA C., et al. Cost-effectiveness of boceprevir or telaprevir for untreated patients with genotype 1 chronic hepatitis C. Hepatology (Baltimore, Md). 2012;56(3):850-60. doi: 10.1002/hep.25734

CAMPIOTTO S., et al. Geographic distribution of hepatitis C virus genotypes in Brazil. Braz J Med Biol Res. 2005;38(1):41-49. DOI: 10.1590/S0100-879X2005000100007

CARDOSO M. N. Projeto Ajude - Brasil II: incidência de Aids e mortalidade em usuários de drogas injetáveis. Belo Horizonte: Faculdade de Medicina da Universidade Federal de Minas Gerais; 2005.

CHOO Q. L., KUO G., WEINER A. J., Overby LR, Bradley DW, Houghton M. Isolation of a cDNA clone derived from a blood-borne non-A, non-B viral hepatitis genome. Science. 1989; 244(4902):359-62.

EASL. EASL Clinical Practice Guidelines: Management of hepatitis C virus infection. J Hepatol. 2011; 55(2):245-64. DOI: 10.1016/j.jhep.2015.03.025

EVERSON G. T., et al. Efficacy of an interferon- and ribavirin-free regimen of daclatasvir, asunaprevir, and BMS-791325 in treatment-naive patients with HCV genotype 1 infection. Gastroenterology. 2014; 146(2):420-429. DOI: 10.1053/j.gastro.2013.10.057.

F FELD J. J., et al. Treatment of HCV with ABT-450/r-ombitasvir and dasabuvir with ribavirin. N Engl J Med. 2014; 370(17):1594-603. DOI: 10.1056/NEJMoa1315722.

FELMLEE D. J., HAFIRASSOU M. L., LEFEVRE M., BAUMERT T. F., SCHUSTER C. Hepatitis C Virus, Cholesterol and Lipoproteins - Impact for the Viral Life Cycle and 
Pathogenesis of Liver Disease. Viruses. 2013;5(5):1292-324. DOI: 10.3390/v5051292

FOCACCIA R, et al. Demographic and anthropometrical analysis and genotype distribution of chronic hepatitis $C$ patients treated in public and private reference centers in Brazil. Braz J Med Biol Res. 2004; 8(5):348-355. DOI: 10.1590/S1413-86702004000500003.

FREEMAN A. J., LAW M. G., KALDOR J. M., DORE G. J. Predicting progression to cirrhosis in chronic hepatitis C virus infection. J Viral Hepat. 2003;10(4):285-293. DOI: 10.1046/j.1365-2893.2003.00436.x.

FRIED M. W., et al. Once-daily simeprevir (TMC435) with pegylated interferon and ribavirin in treatment-naive genotype 1 hepatitis C: the randomized PILLAR study. Hepatology. 2013; 58(6):1918-1929. DOI: 10.1002/hep.26641

FRIED M. W., et al. Peginterferon alfa-2a plus ribavirin for chronic hepatitis $C$ virus infection. N Engl J Med. 2002; 347(13):975-982. DOI: 10.1056/NEJMoa020047

GERLACH J. T., et al. Acute hepatitis C: high rate of both spontaneous and treatmentinduced viral clearance. Gastroenterology. 2003; 125(1):80-88. DOI: 10.1016/S00165085(03)00668-1.

HAYASHI N., OKANOUE T., TSUBOUCHI H., TOYOTA J., CHAYAMA K., KUMADA H. Efficacy and safety of telaprevir, a new protease inhibitor, for difficult-to-treat patients with genotype 1 chronic hepatitis C. J Viral Hepat. 2012; 19(2):e134-142. DOI: 10.1111/j.13652893.2011.01528.x

JACOBSON I. M., et al. Sofosbuvir for hepatitis C genotype 2 or 3 in patients without treatment options. N Engl J Med. 2013; 368(20):1867-1877. DOI: 10.1056/NEJMoa1214854

JACOBSON I. M., et al. Telaprevir for previously untreated chronic hepatitis $\mathrm{C}$ virus infection. N Engl J Med . 2011;364(25):2405-2416. DOI: 10.1056/NEJMoa1012912

KUMADA H., et al. Randomized comparison of daclatasvir+asunaprevir versus Telaprevir +peginterferon/ribavirin in Japanese hepatitis $C$ virus patients. Journal of Gastroenterology 
and Hepatology. 2016; 31(1):14-22. doi: 10.1111/jgh.13073.

KUMADA H., TOYOTA J., OKANOUE T., CHAYAMA K., TSUBOUCHI H., HAYASHI N. Telaprevir with peginterferon and ribavirin for treatment-naive patients chronically infected with HCV of genotype 1 in Japan. J Hepatol. 2012; 56(1):78-84. DOI: 10.1016/j.jhep.2011.07.016

KWO P. Y., et al. Efficacy of boceprevir, an NS3 protease inhibitor, in combination with peginterferon alfa-2b and ribavirin in treatment-naive patients with genotype 1 hepatitis $C$ infection (SPRINT-1): an open-label, randomised, multicentre phase 2 trial. Lancet. 2010; 376(9742):705-716. DOI: 10.1016/S0140-6736(10)60934-8

LANGE C. M., JACOBSON I. M., RICE C. M., ZEUZEM S. Emerging therapies for the treatment of hepatitis C. EMBO Mol Med. 2014;6(1):4-15. DOI: 10.1002/emmm.201303131 LAWITZ E., et al. Sofosbuvir for previously untreated chronic hepatitis $C$ infection. N Engl J Med. 2013; 368(20):1878-1887. DOI: 10.1056/NEJMc1307641.

LAWITZ E., et al. Sofosbuvir in combination with peginterferon alfa-2a and ribavirin for noncirrhotic, treatment-naive patients with genotypes 1,2 , and 3 hepatitis $C$ infection: a randomised, double-blind, phase 2 trial. Lancet Infect Dis. 2013; 13(5):401-408. DOI: 10.1016/S1473-3099(13)70033-1.

LAWITZ E., POORDAD F. F., PANG P. S., HYLAND R. H., DING X., MO H., SYMONDS W. T., MCHUTCHISON J. G., MEMBRENO F. E. Sofosbuvir and ledipasvir fixed-dose combination with and without ribavirin in treatment-naive and previously treated patients with genotype 1 hepatitis $C$ virus infection (LONESTAR): an open-label, randomised, phase 2 trial. Lancet. 2014; 383(9916):515-523. DOI: 10.1016/S0140-6736(13)62121-2

LEROY V., et al. Daclatasvir, sofosbuvir, and ribavirin for hepatitis $C$ virus genotype 3 and advanced liver disease: A randomized phase III study (ALLY-3+). Hepatology (Baltimore, Md). 2016; 63(5):1430-41. doi: 10.1002/hep.28473

LINDENBACH B. D., RICE C. M. The ins and outs of hepatitis $C$ virus entry and assembly. Nat Rev Gastroenterol Hepatol. 2013;11(10):688-700. DOI: 10.1038/nrmicro3098 
MANNS M., et al. All-oral daclatasvir plus asunaprevir for hepatitis C virus genotype 1b: a multinational, phase 3, multicohort study. Lancet. 2014; 384(9954):1597-1605. DOI: 10.1016/S0140-6736(14)61059-X

MANNS M., et al. Ledipasvir and sofosbuvir plus ribavirin in patients with genotype 1 or 4 hepatitis C virus infection and advanced liver disease: a multicentre, open-label, randomised, phase 2 trial. Lancet infectious diseases. 2016; 16(6):685-97. doi: http://dx.doi. org/10.1016/S1473-3099(16)00052-9

MANNS M. P., et al. Peginterferon alfa-2b plus ribavirin compared with interferon alfa-2b plus ribavirin for initial treatment of chronic hepatitis C: a randomised trial. Lancet. 2001; 358(9286):958-965. DOI: 10.1016/S0140-6736(01)06102-5

MENDES-CORRÊA M. C. J., BARONE A. A. Hepatitis C in patients co-infected with human immunodeficiency virus. A review and experience of a Brazilian ambulatory. Rev Inst Med Trop Sao Paulo. 2005;47: 59-64. DOI: 10.1590/S0036-46652005000200001

OLIVEIRA C. V., BARBOSA W. F., SILVEIRA LVDA, MENEZES J., MACHADO F. S., SILVA G. F. Prevalence of the hepatitis C virus among university employees in São Paulo, southeastern Brazil: predictive factors and geoprocessing spatial analysis. Arq Gastroenterol. 2015; 52(1):9-13. DOI: 10.1590/S0004-28032015000100003

P POYNARD T., et al. Randomised trial of interferon alpha2b plus ribavirin for 48 weeks or for 24 weeks versus interferon alpha2b plus placebo for 48 weeks for treatment of chronic infection with hepatitis C virus. Lancet. 1998; 352(9138):1426-1432. DOI: 10.1016/S01406736(98)07124-4

PEARLMAN B. L., EHLEBEN C., PERRYS M. The combination of simeprevir and sofosbuvir is more effective than that of peginterferon, ribavirin, and sofosbuvir for patients with hepatitis C-related Child's class A cirrhosis. Gastroenterology. 2015; 148(4):762-770 54.DOI: 10.1053/j.gastro.2014.12.027

POORDAD F., DIETERICH D. Treating hepatitis C: current standard of care and emerging direct-acting antiviral agents. J Viral Hepat. 2012; 19(7):449-464. DOI: 10.1111/j.1365-2893. 
2012.01617.x.

SHAHID I, W. H. A. L., HAFEEZ M. H., HASSAN S. Hepatitis C virus infection treatment: An era of game changer direct acting antivirals and novel treatment strategies. Critical reviews in microbiology. 2016; 42(4):535-47. doi: 10.3109/1040841X.2014.970123

SMITH D. B., BUKH J., KUIKEN C., MUERHOFF A. S., RICE C. M., STAPLETON J. T., SIMMONDS P. Expanded classification of hepatitis $C$ virus into 7 genotypes and 67 subtypes: updated criteria and genotype assignment web resource. Hepatology. 2014; 59(1):318-327. DOI: doi: 10.1002/hep.26744

SULKOWSKI M. S., COOPER C., HUNYADY B., JIA J., OGURTSOV P., PECKRADOSAVLJEVIC M., SHIFFMAN M. L., YURDAYDIN C., DALGARD O. Management of adverse effects of Peg-IFN and ribavirin therapy for hepatitis C. Nat Rev Gastroenterol Hepatol. 2011;8(4):212-23. DOI: 10.1038/nrgastro.2011.21

THOMSON E. C., FLEMING V. M., MAIN J., KLENERMAN P., WEBER J., ELIAHOO J., SMITH J., MCCLURE M. O., KARAYIANNIS P. Predicting spontaneous clearance of acute hepatitis $C$ virus in a large cohort of HIV-1-infected men. Gut. 2011; 60(6):837-845. DOI: 10.1136/gut.2010.217166

WARD R. P., KUGELMAS M. Using pegylated interferon and ribavirin to treat patients with chronic hepatitis C. Am Fam Physician. 2005; 72(4):655-662.

WITTHOFT T., et al. Safety, tolerability and efficacy of peginterferon alpha-2a and ribavirin in chronic hepatitis C in clinical practice: The German Open Safety Trial. J Viral Hepat. 2007; 14(11):788-796. DOI: 10.1111/j.1365-2893.2007.00871.x

World Health Organization (WHO). Guidelines for the Screening, Care and Treatment of Persons with Hepatitis C Infection Geneva: World Health Organization. 2014.

YAU A. H., YOSHIDA E. M. Hepatitis $C$ drugs: the end of the pegylated interferon era and the emergence of all-oral interferon-free antiviral regimens: a concise review. Can $\mathrm{J}$ Gastroenterol Hepatol. 2014; 28(8):445-451. 
YOUNOSSI Z. M., et al. Patient-reported outcomes assessment in chronic hepatitis C treated with sofosbuvir and ribavirin: the VALENCE study. J Hepatol. 2014;61(2):228-234. DOI: 10.1016/j.jhep.2014.04.003

ZEUZEM S., et al. Daclatasvir plus simeprevir with or without ribavirin for the treatment of chronic hepatitis C virus genotype 1 infection. J Hepatol. 2016; 64(2):292-300. DOI: 10.1016/j.jhep.2015.09.024 